\title{
Human caliciviruses detected in HIV-seropositive children
}

\section{in Kenya}

Dr. Janet Mans ${ }^{1}$, Dr. Tanya Y. Murray ${ }^{1}$, Mr. Nicholas M. Kiulia ${ }^{2}$, Dr. Jason M.

Mwenda $^{2}$, Prof. Rachel N. Musoke ${ }^{3}$, and Prof. Maureen B. Taylor ${ }^{1,4}$

1) Department of Medical Virology, University of Pretoria, Private Bag X323, Arcadia, 0007, Pretoria, South Africa

2) Enteric Viruses Research Group, Institute of Primate Research, P.O. Box 24481, 00502, Karen, Nairobi, Kenya

3) Department of Paediatrics and Child Health, College of Health Sciences, University of Nairobi, P.O. Box 19676 - 00202KNH, Nairobi, Kenya

4) National Health Laboratory Service, Tshwane Academic Division, Pretoria, South Africa

\section{Corresponding author:}

Dr. Janet Mans

Department of Medical Virology

University of Pretoria

Private Bag X323, Arcadia 0007, Pretoria, South Africa

Tel: +27 123192534

Fax: +27 123255550

Email: janet.mans@,tuks.co.za

Running head: Caliciviruses in HIV-positive children 


\section{ABSTRACT}

The human caliciviruses (HuCVs) are important causes of gastroenteritis worldwide. Norovirus (NoV) and sapovirus (SaV) have been detected in HIV-seropositive children but the genetic diversity of HuCVs circulating in these individuals is largely unknown. In this study the prevalence and genotype diversity of HuCVs circulating in Kenyan HIV-positive children, with or without diarrhoea, from the year 1999 to 2000 was investigated. The overall prevalence of $\mathrm{HuCVs}$ was $19 \%$ with $\mathrm{NoV}$ predominating at $17 \%(18 / 105)$ and $\mathrm{SaV}$ present in $5.7 \%(6 / 105)$ of specimens. Human CVs were detected in both symptomatic (24\%) and asymptomatic (16\%) children. Co-infections with other enteric viruses were detected in $21.6 \%$ of children with diarrhoea but only in $4.4 \%$ of children without diarrhoea. Remarkable genetic diversity was observed with 12 genotypes ( $7 \mathrm{NoV}, 5 \mathrm{SaV}$ ) being identified in 20 HuCV-infected children. NoV genogroup II (GII) strains predominated with GII.2 and GII.4 each representing $27 \%$ of the NoV-positive strains. The GII.4 strain was most closely related to the non-epidemic GII.4 Kaiso 2003 variant. Other NoV genotypes detected were GI.3, GII.6, GII.12, GII.14 and GII.17. Five different SaV genotypes (GI.2, GI.6, GII.1, GII.2 and GII.4) were characterised from six specimens.

Diarrhoeal symptoms were not associated with any specific HuCV genotype. Overall the HuCV genotype distribution detected in this study reflects those in other studies worldwide. The strains detected are closely related to genotypes that have circulated on several continents since the year 2000 .

\section{KEYWORDS}

norovirus, sapovirus, diarrhoea, paediatric, Africa 


\section{INTRODUCTION}

Norovirus (NoV) and sapovirus (SaV) are classified within the Caliciviridae family and are important causes of viral gastroenteritis [Green, 2007]. These small nonenveloped viruses have a single-stranded positive-sense RNA genome, are genetically diverse and NoVs have been shown to have a very low infectious dose [Teunis et al., 2008]. Both NoVs and $\mathrm{SaVs}$ are classified into genogroups based on the major capsid protein sequence. Noroviruses and $\mathrm{SaVs}$ are each divided into at least five genogroups (G), of which NoV GI, GII and GIV [Zheng et al., 2006] and SaV GI, GII, GIV and GV [Farkas et al., 2004] infect humans.

In healthy individuals human caliciviruses (HuCVs) cause self-limiting disease with resolution of symptoms within 1-6 days followed by a variable period of virus shedding (1-3 weeks) [Rockx et al., 2002]. However, chronic NoV infection has been documented in persons undergoing immunosuppressive therapy as well as in human immunodeficiency virus (HIV)-positive patients [Wingfield et al., 2010; Bok and Green, 2012]. Early HuCV prevalence studies in HIV-seropositive children and/or adults using electron microscopy or enzyme immunoassays (EIA) did not detect any HuCVs or reported low frequencies [Gonzalez et al., 1998; Nakata et al., 1998]. More recent investigations that applied molecular-based assays have detected HuCVs in HIV-infected individuals with prevalences ranging from $12 \%$ to $20 \%$ [RodriguezGuillen et al., 2005; Ayukekbong et al., 2011]. Nevertheless, similar HuCV detection rates were reported in HIV-negative persons, indicating that although HIV-positive individuals are often infected with $\mathrm{HuCVs}$, there is no association between HIV status and $\mathrm{HuCV}$ gastroenteritis. Few studies have examined HuCV genotype diversity in 
HIV-infected patients. In Venezuela the Lordsdale NoV strain (GII.4) and the London/92 SaV strain (GII.1) have been reported in HIV-positive children [Rodriguez-Guillen et al., 2005]. Recently the NoV GII.4, GII.8 and GII.17 strains were identified in non-diarrhoeal stool specimens from HIV-positive adults in Cameroon [Ayukekbong et al., 2011]. In Kenya very little is known about the prevalence of HuCVs and the diversity of the circulating genotypes. From 1991 and 1994, an epidemiological survey in the Nairobi area reported serum antibody prevalence in adults ranging between $60 \%$ for NoV GI to $80-90 \%$ for NoV GII and $\mathrm{SaV}$ [Nakata et al., 1998]. In the same study Norwalk virus (GI.1), Mexico virus (GII.3) and Sapporo virus (GI.1) were detected by EIA in stool specimens from infants [Nakata et al., 1998].

A significant number of individuals (around 22.9 million) in Africa live with HIV/acquired immunodeficiency syndrome (AIDS) [De Cock et al., 2012] and general diarrhoea is common in HIV-infected individuals. It is therefore important to determine the prevalence of HuCVs and to assess whether the strains circulating in HIV-infected individuals reflect those found in the community. In this study the prevalence and genotype diversity of HuCVs circulating in a group of Kenyan HIVpositive children, with or without diarrhoea, from the year 1999 to 2000 were investigated. 


\section{MATERIALS AND METHODS}

\section{Ethical approval}

This study was approved by the Kenyatta National Hospital Ethics and Research Committee (KNH-ERC) and the Faculty of Health Sciences Research Ethics Committee, University of Pretoria, South Africa Protocol 138-2008.

\section{Study patients and specimen collection}

From February 1999 to June 2000, as part of an on-going public health initiative by the WHO co-ordinated African Rotavirus Network to document rotavirus infection and epidemiology in Kenya, 105 stool specimens (37 diarrhoeal; 68 non-diarrhoeal) were collected from HIV-seropositive children of varying ages but all $<14$ years of age (mean 6.3) at the Children of God Relief Institute (COGRI) children's home and home-based programme. Diarrhoeal specimens were defined as loose/watery stool whereas non-diarrhoeal specimens were defined as formed stool at the time of collection. These samples had all previously been tested for rotaviruses [Kiulia et al., 2009], astroviruses [Kiulia et al., 2007] and adenoviruses (AdVs) [Magwalivha et al., 2010].

\section{Specimen preparation and nucleic acid extraction}

Stool suspensions $(10 \%)$ were prepared in ultrapure water and stored at $-20^{\circ} \mathrm{C}$ until nucleic acid extraction. Total nucleic acids were extracted from $200 \mu 1$ stool suspension using the MagNA Pure LC Total Nucleic Acid Isolation kit (Roche Diagnostics, Mannheim, Germany) on the automated MagNA Pure system (Roche Diagnostics). The nucleic acids were eluted in $50 \mu \mathrm{l}$ and stored at $-70^{\circ} \mathrm{C}$ until use. 


\section{Detection of human caliciviruses}

Norovirus GI and GII were detected with published one-step real-time reverse transcription-polymerase chain reaction (RT-PCR) assays targeting the ORF1/ORF2 junction [Mans et al., 2010]. Specimens were screened for NoV GIV [Trujillo et al., 2006; Murray et al., 2013a] and SaV [Chan et al., 2006; Murray et al., 2013b] as previously described.

\section{Genotyping}

Norovirus GI and GII strains were genotyped based on nucleotide sequence determination and phylogenetic analysis of the $5^{\prime}$-end of the capsid gene (Region C) using a semi-nested RT-PCR as described previously [Mans et al., 2013]. Briefly, a first round of amplification was performed with primer pairs QNIF4/G1SKR for NoV GI and QNIF2/G2SKR for NoV GII. If no PCR products were obtained after this step, a second amplification was performed using primes G1SKF/G1SKR and G2SKF/ G2SKR. Sapoviruses were genotyped based on partial capsid gene nucleotide sequences (approximately 300 bp) as described previously [Kitajima et al., 2010; Sano et al., 2011; Murray et al., 2013a]. The PCR products were purified with the DNA Clean and Concentrater kit (Zymo Research, Irvine, CA) and directly sequenced with the ABI PRISM BigDye ${ }^{\circledR}$ Terminator v. 3.1 Cycle Sequencing kit on an ABI 3130 automated analyser (Applied Biosystems, Foster City, CA). Nucleotide sequences were edited and analysed using SequencherTM 4.9 (Gene Codes Corporation, Ann Arbor, MI) and BioEdit Sequence Alignment Editor (V.7.0.9.0) [Hall, 1999]. 


\section{Phylogenetic analysis}

Phylogenetic analysis of NoV GI, GII and SaV was performed in MEGA5 using the neighbour-joining method, validated by 1000 bootstrap replicates as described previously [Murray et al., 2013a]. Genotypes were assigned based on clustering with reference strains in the phylogenetic tree with $>70 \%$ bootstrap support. The Norovirus Genotyping Tool [Kroneman et al., 2011] was used to confirm the NoV genotype assignment. Nucleotide sequences determined in this study were submitted to GenBank under accession numbers: KF279373-KF279391 (NoV) and KF267740KF267745 (SaV).

\section{Statistical analysis}

Statistical significance was determined by calculating a $2 \times 2$ contingency table using the Fischer's Exact test with Graphpad Quickcalcs (www.graphpad.com/quickcalcs/contingency2/). P values $<0.05$ were considered statistically significant.

\section{RESULTS}

Human CVs were detected in 19\% (18/105 NoV, 6/105 SaV) of stool specimens from HIV-positive children from the COGRI children's home and home-based programme in Nairobi, Kenya. NoV GII represented 16/18 (88.8\%) of the NoV infections, NoV GI was detected in 1/18 (5.5\%) of specimens and a single GI/GII mixed infection was identified. All specimens tested negative for NoV GIV. Sapovirus GI and GII were

each detected in $3 / 6(50 \%)$ specimens (Table I). Human CVs were detected in $24 \%$ of children with diarrhoea and in $16 \%$ of children without diarrhoeal symptoms but the 
difference was not statistically significant $(\mathrm{p}=0.3130$, Table I). For both NoVs and SaVs, GI and GII were detected at similar frequencies between symptomatic and asymptomatic children.

The co-infections observed between other enteric viruses and HuCVs are summarised in Table II. Up to two different viruses were detected in symptomatic and asymptomatic children, while three viruses were detected only in children with diarrhoea. Co-infections between NoV GII, SaV and AdV were detected most frequently. Overall 12 different genotypes (Table I) were identified in the $20 \mathrm{HuCV}$ positive specimens. The NoV strains could be classified into seven (1 GI, 6 GII) genotypes (Fig. 1). Strains GII.2 and GII.4 were detected most often (5/18 specimens each) followed by GI.3 (2), GII.6 (2), GII.12 (2), GII.14 (2) and GII.17 (1). Five different SaV genotypes (GI.1, GI.6, GII.1, GII.2, GII.4) were detected in the six positive specimens with GI.2 being identified in two specimens (Fig. 2). Out of the five $\mathrm{SaV}$ genotypes, GI.2, GII.1 and GII.2 were detected in children with diarrhoea and GI.6 and GII.4 were identified in children without diarrhoea. The different NoV genotypes were found with similar frequencies in diarrhoeal and non-diarrhoeal specimens. In addition, identical NoV strains were detected in both symptomatic and asymptomatic children. GI.3 and GII.14 were identified in the single sample with a NoV mixed infection. There were four mixed infections with NoV GII and SaV, three of which were also co-infected with AdV. Human CV genotypes present in these coinfections included NoV GII.2, GII.4 and GII.14 and SaV GI.2, GI.6 and GII.1. Diverse GI.3 and GII.6 NoV strains were characterised, while the multiple strains from the other genotypes were highly similar or identical (Fig. 1). The GII.4 strains could not be assigned to a GII.4 variant group by either the neighbour-joining analysis 
TABLE I. Human caliciviruses detected in stool specimens from HIV-positive children with and without diarrhoea.

\begin{tabular}{|c|c|c|c|c|}
\hline \multirow{2}{*}{ Virus" } & \multicolumn{2}{|c|}{ No. of children with virus (\%) } & \multirow[b]{2}{*}{ P-value } & \multirow[b]{2}{*}{ Genotypes } \\
\hline & Diarrhoea $(n=37)$ & Non-diarrhoeal $(n=68)$ & & \\
\hline NoV GI & 0 & $1(1.5)$ & - & GI.3 \\
\hline NoV GII & $7(18.9)$ & $9(13.2)$ & 0.5707 & GII.2, GII.4, GII.6, GII.12, GII.14, GII.17 \\
\hline $\mathrm{NoV}$ GI + GII & 1(2.7) & 0 & - & GI.3, GII.14 \\
\hline $\mathrm{SaV}$ & $4(10.8)$ & $2(2.9)$ & 0.1819 & GI.2, GI.6, GII.1, GII.2, GII.4 \\
\hline Total HuCV & $9(24.3)$ & $11(16.2)$ & 0.3130 & \\
\hline
\end{tabular}

*All specimens tested negative for NoV GIV.

TABLE II. Co-infection of human caliciviruses (NoV GI, GII and SaV) with human adenovirus (AdV), human astrovirus (AstV) and rotavirus (RV) in HIV-positive children with and without diarrhoeal symptoms.

\section{HIV-positive children}

\begin{tabular}{|c|c|c|c|}
\hline No. of viruses & Virus combination & $\begin{array}{c}\text { Diarrhoea }(\mathbf{n}=\mathbf{3 7}) \\
\text { No. of positive specimens (\%) }\end{array}$ & $\begin{array}{c}\text { Non-diarrhoeal (n=68) } \\
\text { No. of positive specimens (\%) }\end{array}$ \\
\hline \multirow{4}{*}{ Two } & $\mathrm{NoV}$ GII + AdV & $1(2.7)$ & 0 \\
\hline & NoV GII + RV & 0 & $1(1.5)$ \\
\hline & $\mathrm{NoV}$ GII + SaV & 0 & $1(1.5)$ \\
\hline & $\mathrm{SaV}+\mathrm{AdV}$ & $1(2.7)$ & $1(1.5)$ \\
\hline \multirow{4}{*}{ Three } & $\mathrm{NoV} \mathrm{GI}+\mathrm{GII}+\mathrm{AdV}$ & $1(2.7)$ & 0 \\
\hline & $\mathrm{NoV}$ GII $+\mathrm{SaV}+\mathrm{AdV}$ & $3(8.1)$ & 0 \\
\hline & NoV GII + AdV + AstV & $1(2.7)$ & 0 \\
\hline & NoV GII + AdV + RV & $1(2.7)$ & 0 \\
\hline Total & & $8(21.6)$ & $3(4.4)$ \\
\hline
\end{tabular}




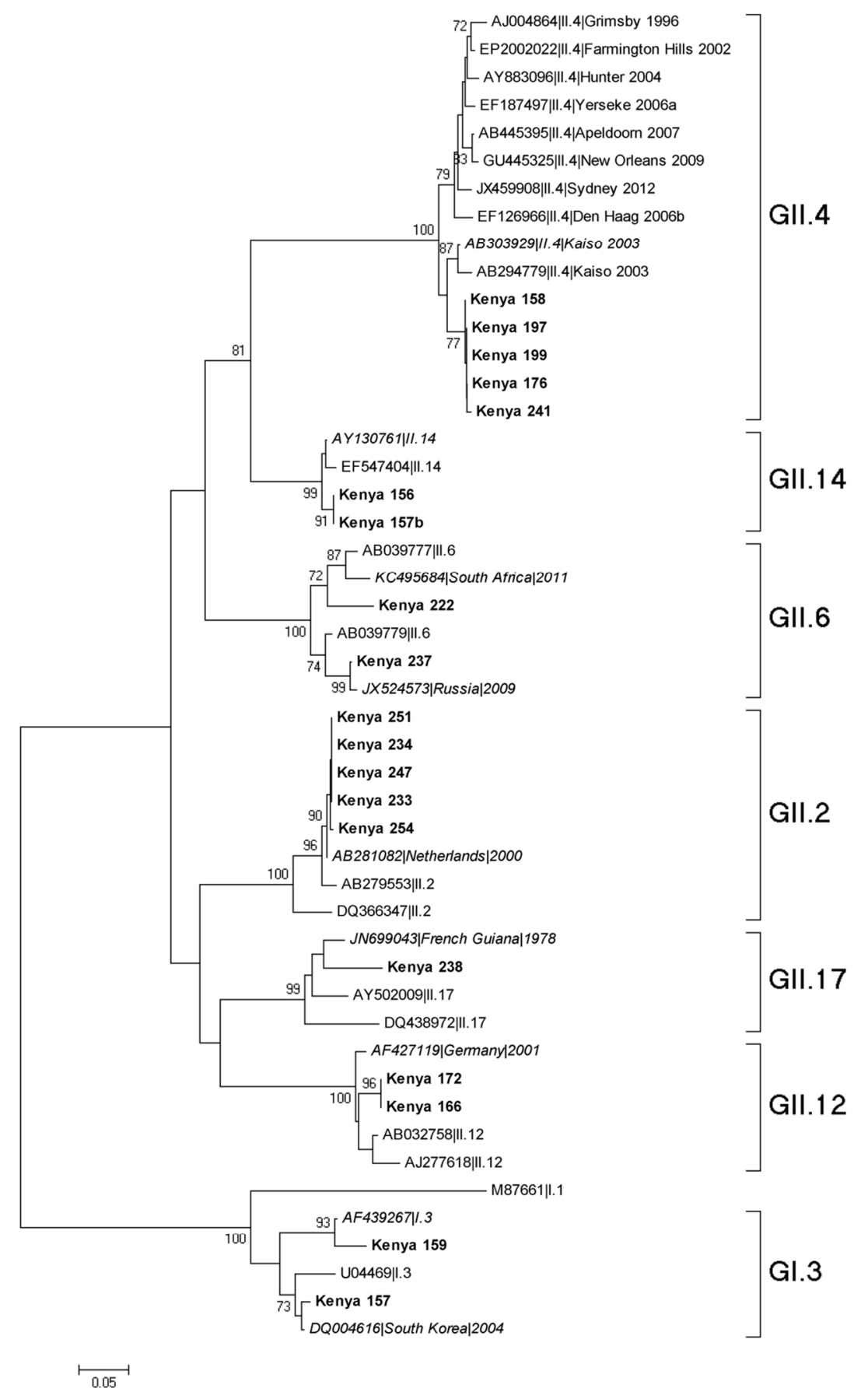

Fig. 1. Neighbour-joining phylogenetic analysis of partial capsid sequences (288 nucleotides) of 19 NoV strains identified in HIV-positive children in Kenya and $25 \mathrm{NoV}$ GI and GII reference sequences. Bootstrap values $>70$ are shown at the branch nodes. The evolutionary distances were computed using the Kimura 2-parameter model as implemented in MEGA5. Samples from this study are shown in boldface and the most closely matched sequences detected in GenBank with BLAST are italicised. 


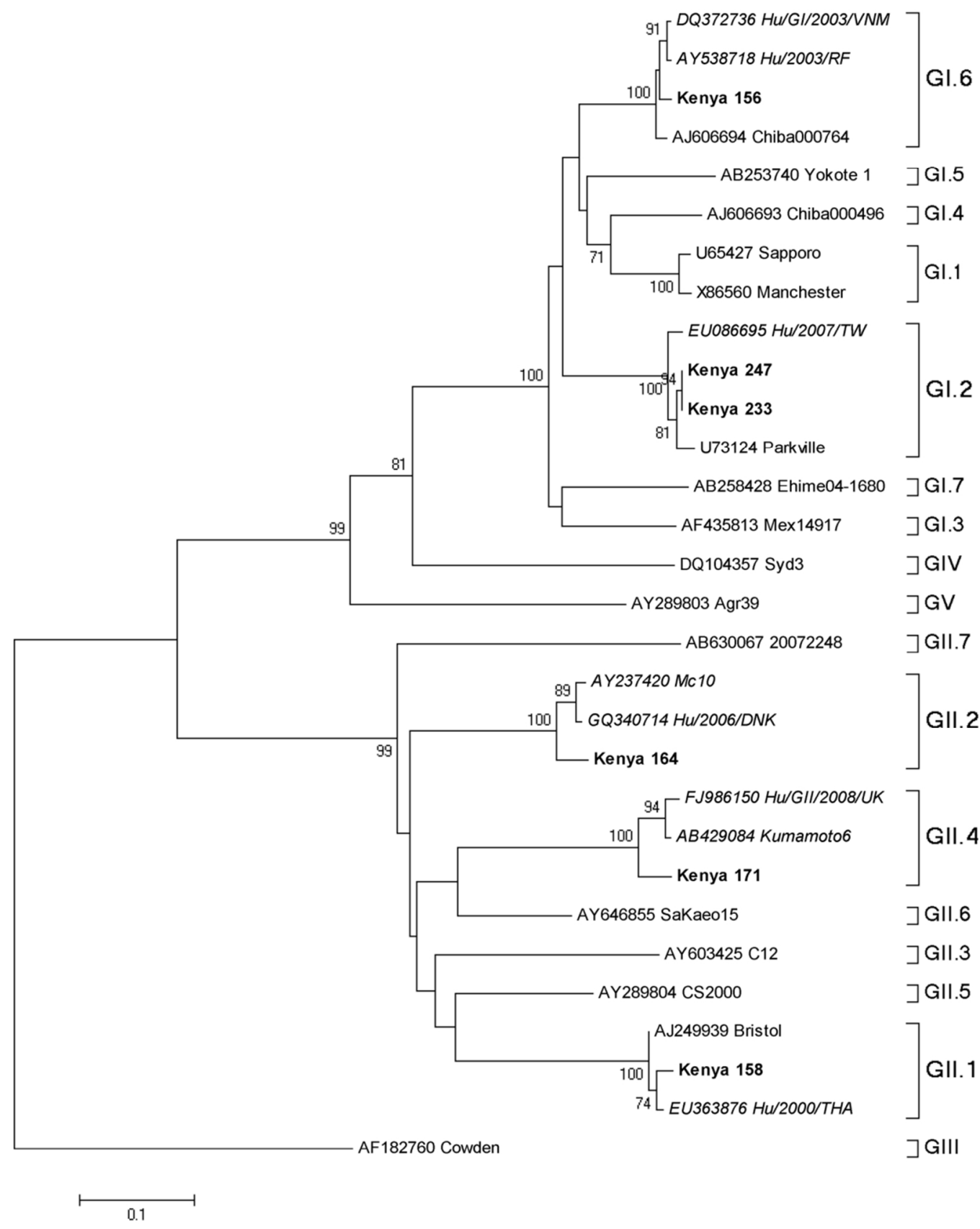

Fig. 2. Neighbour-joining phylogenetic analysis of partial capsid sequences (307 nucleotides) of $6 \mathrm{SaV}$ strains identified in HIV-positive children in Kenya and $\mathrm{SaV}$ reference sequences. Bootstrap values $>70$ are shown at the branch nodes. The evolutionary distances were computed using the Kimura 2-parameter model as implemented in MEGA5. Samples from this study are shown in boldface and the most closely matched sequences detected in GenBank with BLAST are italicised. 
(bootstrap support=64\%) shown in Figure 1 or by the online NoV genotyping tool. The closest match on GenBank, strain AB303929, is the reference strain for the GII.4 Kaiso 2003 variant and the Kenya strains are 98\% identical to this sequence over 287 nucleotides of the 5 '-end of the capsid gene.

\section{DISCUSSION}

Few studies have investigated the prevalence of HuCVs in HIV-infected children using molecular methods. Several research groups have concluded that there is no significant association between HuCVs and diarrhoea in HIV-infected children or adults [Gonzalez et al., 1998; Rodriguez-Guillen et al., 2005]. However, HuCVs were found more frequently in HIV-infected than uninfected children, suggesting that HuCVs might be opportunistic pathogens in HIV-infected children [RodriguezGuillen et al., 2005]. The HuCV genotypes circulating in HIV-infected children are largely unknown. This study investigated the prevalence and genetic diversity of HuCVs in a group of HIV-infected children in Kenya, providing valuable data on NoVs and SaVs in Africa.

Reported NoV and $\mathrm{SaV}$ prevalence rates in paediatric patients with gastroenteritis vary considerably, with NoV ranging from 6-48\% (median 14\%) [Koopmans, 2008] and $\mathrm{SaV}$ ranging from 0.4-19\% [Harada et al., 2009; Lorrot et al., 2011]. These studies did not report HIV-status, however it is likely that a negligible portion of the study patients were HIV-seropositive. The HuCV prevalence of $19 \%$ (17\% NoV, $5.7 \% \mathrm{SaV}$ ) found in this study corresponds to these previously reported rates. The

prevalence was lower than that observed in a study in Venezuela where HuCVs were 
detected in 51\% (22/43) of HIV-infected children [Rodriguez-Guillen et al., 2005]. The Venezuelan study was performed around the same time period (1997-1998) but focused on infants (mean age - 19 months) whereas the mean age of the children in the current study was 6.3 years. This may explain the difference in prevalence since higher HuCV positivity rates have been reported in children $<3$ years of age [Murata et al., 2007; Phan et al., 2007; Oldak et al., 2012; Trang et al., 2012]. In this study, as well as the Venezuelan study [Rodriguez-Guillen et al., 2005], HuCVs were more frequently detected in children with diarrhoea than without. However in both studies this difference was not statistically significant. Since in the Kenyan study diarrhoeal and non-diarrhoeal stool specimens were defined as loose/watery stool and formed stool, respectively, $\mathrm{HuCV}$-infected non-diarrhoeal specimens may not all represent asymptomatic infections. At the time of sample collection (1999-2000) prolonged viral shedding was not well established and consequently a defined diarrhoea-free period prior to specimen collection was not incorporated in the study design. In addition, chronic NoV shedding with or without clinical symptoms has been described in immunocompromised patients, such as renal transplant recipients [Schorn et al., 2010], which could explain similar HuCV prevalences in symptomatic and asymptomatic HIV-infected children. Co-infections between HuCVs and other enteric viruses were associated with diarrhoeal symptoms $(\mathrm{p}=0.0152)$. In contrast, a study in Cameroon detected co-infections of up to five enteric viruses in healthy HIVuninfected children [Ayukekbong et al., 2011]. This may suggest that HIV-infected children are more likely to have diarrhoeal symptoms when infected with multiple enteric viruses than HIV-uninfected children. However, since there are no data on bacterial or parasitic infections in these children these cannot be excluded as causes for diarrhoeal symptoms. 
The NoV genogroup distribution in HIV-infected children determined in this study reflects the global trends with $89 \%$ NoV GII and 5.5\% NoV GI and 5.5\% mixed infections [Hoa Tran et al., 2013]. Over a period of 17 months, seven NoV genotypes circulated among 18/105 HIV-seropositive children in Nairobi, Kenya. Three of the globally prevalent NoV genotypes (GII.2, GII.4, GII.6) were detected in these children. NoV GII.2 and GII.4 each represented $27 \%$ of the NoV infections. This is in contrast with other studies from Africa [Sdiri-Loulizi et al., 2009], Asia [Cheng et al., 2010], Europe [Puustinen et al., 2012] and South America [Barreira et al., 2010] that report GII.4 as the predominant genotype. In this study a single GII.4 variant was detected in the children. This strain is most closely related to the non-epidemic GII.4 Kaiso 2003 variant that circulated in the Netherlands [Siebenga et al., 2007] and Japan during 2002 and 2003 [Okada et al., 2007] and was subsequently detected in Australia [Eden et al., 2010] and Egypt [Kamel et al., 2009] in 2007. Of note, no NoV GII.3 strains, which appear to be the second most prevalent genotype in children [Hoa Tran et al., 2013] were detected in the present study. The other NoV genotypes detected in this study (GI.3, GII.12, GII.14, GII.17) have been reported at low frequencies on several continents [Cheng et al., 2010; Ferreira et al., 2012; Greening et al., 2012; Puustinen et al., 2012].

The five $\mathrm{SaV}$ genotypes identified in this study have all previously been reported in children with gastroenteritis [Phan et al., 2007; Harada et al., 2012; Trang et al., 2012]. Genotypes II.2 and II.4 have also been detected in asymptomatic children in India [Monica et al., 2007]. The SaV strains from Kenya were closely-matched (9598\% nucleotide identity) to SaVs from several other countries, including Denmark 
(GII.2), Japan and the United Kingdom (GII.4), Russia and Vietnam (GI.6), Taiwan (GI.2) and Thailand (GII.1). Prior to this study, SaV GII.1 was the only SaV genotype which had been characterised from HIV-seropositive children with gastroenteritis [Rodriguez-Guillen et al., 2005] and it was also detected in a symptomatic child in this study. Sapovirus GI.2 was the only genotype which was identified in two specimens and it has recently been reported as a predominant $\mathrm{SaV}$ genotype associated with outbreaks and sporadic cases of gastroenteritis in children [Miyoshi et al., 2010; Svraka et al., 2010; Medici et al., 2012].

The number of $\mathrm{HuCV}$ genotypes ( $7 \mathrm{NoV}$ and $5 \mathrm{SaV}$ ) characterised in this study is high compared to the diversity seen in studies with larger sample sizes. A study in Tunisia involving 788 patients identified eight different NoV genotypes from 128 NoV-positive specimens [Sdiri-Loulizi et al., 2009]. In Brazil, six NoV genotypes were found in $52 \mathrm{NoV}$-positive specimens from a total of 319 children [Barreira et al., 2010]. With regards to $\mathrm{SaV}$, a study in Japan identified eight different genotypes from $58 \mathrm{SaV}$-positive specimens over a four-year period [Harada et al., 2012]. In Denmark, a large-scale study ( $\mathrm{n}=1104)$ on $\mathrm{SaVs}$ found six different genotypes in 80 SaV-positive specimens from paediatric patients with gastroenteritis [Johnsen et al., 2009].

A remarkably high diversity of $\mathrm{HuCV}$ s was characterised from a small number of HIV-seropositive children in Kenya. To establish whether this observation is characteristic of co-infection of HIV and HuCVs, further studies including a larger sample size of HIV-infected and uninfected children from a similar socio-economic setting are necessary. An up-to-date investigation would determine whether recently 
emerged GII.4 viruses are circulating in Kenya and if these strains predominate in NoV infections in HIV-infected individuals.

\section{ACKNOWLEDGEMENTS}

The authors would like to acknowledge the Poliomyelitis Research Foundation (PRF) of SA for research funding (Grant number 09/33). TY Murray was supported by a $\mathrm{PhD}$ fellowship from the PRF and acknowledges a PhD bursary from the National Research Foundation of South Africa (NRF). J Mans was supported by a postdoctoral fellowship from the University of Pretoria. This work is based on research supported in part by the NRF (77655). The Grantholder acknowledges that opinions, findings and conclusions or recommendations expressed in any publication generated by NRF supported research are that of the author(s), and that the NRF accepts no liability whatsoever in this regard.

\section{REFERENCES}

Ayukekbong J, Lindh M, Nenonen N, Tah F, Nkuo-Akenji T, Bergstrom T. 2011. Enteric viruses in healthy children in Cameroon: viral load and genotyping of norovirus strains. J Med Virol 83:2135-2142.

Barreira DM, Ferreira MS, Fumian TM, Checon R, de Sadovsky AD, Leite JP, Miagostovich MP, Spano LC. 2010. Viral load and genotypes of noroviruses in symptomatic and asymptomatic children in Southeastern Brazil. J Clin Virol 47:60-64.

Bok K, Green KY. 2012. Norovirus gastroenteritis in immunocompromised patients. N Engl J Med 367:2126-2132.

Chan MC, Sung JJ, Lam RK, Chan PK, Lai RW, Leung WK. 2006. Sapovirus detection by quantitative real-time RT-PCR in clinical stool specimens. J Virol Methods 134:146-153.

Cheng WX, Ye XH, Yang XM, Li YN, Jin M, Jin Y, Duan ZJ. 2010. Epidemiological study of human calicivirus infection in children with gastroenteritis in Lanzhou from 2001 to 2007. Arch Virol 155:553-555.

De Cock KM, Jaffe HW, Curran JW. 2012. The evolving epidemiology of HIV/AIDS. AIDS 26:1205-1213. 
Eden JS, Bull RA, Tu E, McIver CJ, Lyon MJ, Marshall JA, Smith DW, Musto J, Rawlinson WD, White PA. 2010. Norovirus GII.4 variant 2006b caused epidemics of acute gastroenteritis in Australia during 2007 and 2008. J Clin Virol 49:265-271.

Farkas T, Zhong WM, Jing Y, Huang PW, Espinosa SM, Martinez N, Morrow AL, Ruiz-Palacios GM, Pickering LK, Jiang X. 2004. Genetic diversity among sapoviruses. Arch Virol 149:1309-1323.

Ferreira MS, Xavier Mda P, Tinga AC, Rose TL, Fumian TM, Fialho AM, de Assis RM, Carvalho Costa FA, de Oliveira SA, Leite JP, Miagostovich MP. 2012. Assessment of gastroenteric viruses frequency in a children's day care center in Rio De Janeiro, Brazil: a fifteen year study (1994-2008). PLoS One 7:e33754.

Gonzalez GG, Pujol FH, Liprandi F, Deibis L, Ludert JE. 1998. Prevalence of enteric viruses in human immunodeficiency virus seropositive patients in Venezuela. J Med Virol 55:288-292.

Green K. 2007. Caliciviridae: The Noroviruses. In: Knipe DM, Howley PM, Griffin DE, Lamb RA, Martin MA, Roizman B, Straus SE, editors. Field's Virology Fifth Edition ed. Philadelphia: Lippincott Williams \& Wilkins. p 949-979.

Greening GE, Hewitt J, Rivera-Aban M, Croucher D. 2012. Molecular epidemiology of norovirus gastroenteritis outbreaks in New Zealand from 2002-2009. J Med Virol 84:1449-1458.

Hall TA. 1999. BioEdit: a user-friendly biological sequence alignment editor and analysis program for Windows 95/98/NT. Nucl Acids Symp Ser 41:95-98.

Harada S, Oka T, Tokuoka E, Kiyota N, Nishimura K, Shimada Y, Ueno T, Ikezawa S, Wakita T, Wang Q, Saif LJ, Katayama K. 2012. A confirmation of sapovirus re-infection gastroenteritis cases with different genogroups and genetic shifts in the evolving sapovirus genotypes, 2002-2011. Arch Virol 157:1999-2003.

Harada S, Okada M, Yahiro S, Nishimura K, Matsuo S, Miyasaka J, Nakashima R, Shimada Y, Ueno T, Ikezawa S, Shinozaki K, Katayama K, Wakita T, Takeda N, Oka T. 2009. Surveillance of pathogens in outpatients with gastroenteritis and characterization of sapovirus strains between 2002 and 2007 in Kumamoto Prefecture, Japan. J Med Virol 81:1117-1127.

Hoa Tran TN, Trainor E, Nakagomi T, Cunliffe NA, Nakagomi O. 2013. Molecular epidemiology of noroviruses associated with acute sporadic gastroenteritis in children: global distribution of genogroups, genotypes and GII.4 variants. J Clin Virol 56:185-193.

Johnsen CK, Midgley S, Bottiger B. 2009. Genetic diversity of sapovirus infections in Danish children 2005-2007. J Clin Virol 46:265-269.

Kamel AH, Ali MA, El-Nady HG, de Rougemont A, Pothier P, Belliot G. 2009. Predominance and circulation of enteric viruses in the region of Greater Cairo, Egypt. J Clin Microbiol 47:1037-1045.

Kitajima M, Oka T, Haramoto E, Katayama H, Takeda N, Katayama K, Ohgaki S. 2010. Detection and genetic analysis of human sapoviruses in river water in Japan. Appl Environ Microbiol 76:2461-2467.

Kiulia NM, Mwenda JM, Nyachieo A, Nyaundi JK, Steele AD, Taylor MB. 2007. Astrovirus infection in young Kenyan children with diarrhoea. J Trop Pediatr 53:206-209. 
Kiulia NM, Nyaundi JK, Peenze I, Nyachieo A, Musoke RN, Steele AD, Mwenda JM. 2009. Rotavirus infections among HIV-infected children in Nairobi, Kenya. J Trop Pediatr 55:318-323.

Koopmans M. 2008. Progress in understanding norovirus epidemiology. Curr Opin Infect Dis 21:544-552.

Kroneman A, Vennema H, Deforche K, v d Avoort H, Penaranda S, Oberste MS, Vinje J, Koopmans M. 2011. An automated genotyping tool for enteroviruses and noroviruses. J Clin Virol 51:121-125.

Lorrot M, Bon F, El Hajje MJ, Aho S, Wolfer M, Giraudon H, Kaplon J, Marc E, Raymond J, Lebon P, Pothier P, Gendrel D. 2011. Epidemiology and clinical features of gastroenteritis in hospitalised children: prospective survey during a 2-year period in a Parisian hospital, France. Eur J Clin Microbiol Infect Dis 30:361-368.

Magwalivha M, Wolfaardt M, Kiulia NM, van Zyl WB, Mwenda JM, Taylor MB. 2010. High prevalence of species D human adenoviruses in fecal specimens from Urban Kenyan children with diarrhea. J Med Virol 82:77-84.

Mans J, de Villiers JC, du Plessis NM, Avenant T, Taylor MB. 2010. Emerging norovirus GII.4 2008 variant detected in hospitalised paediatric patients in South Africa. J Clin Virol 49:258-264.

Mans J, Netshikweta R, Magwalivha M, van Zyl WB, Taylor MB. 2013. Diverse norovirus genotypes identified in sewage-polluted river water in South Africa. Epidemiol Infect 141:303-313.

Medici MC, Tummolo F, Albonetti V, Abelli LA, Chezzi C, Calderaro A. 2012. Molecular detection and epidemiology of astrovirus, bocavirus, and sapovirus in Italian children admitted to hospital with acute gastroenteritis, 2008-2009. J Med Virol 84:643-650.

Miyoshi M, Yoshizumi S, Kanda N, Karino T, Nagano H, Kudo S, Okano M, Ishida S. 2010. Different genotypic sapoviruses detected in two simultaneous outbreaks of gastroenteritis among schoolchildren in the same school district in Hokkaido, Japan. Jpn J Infect Dis 63:75-78.

Monica B, Ramani S, Banerjee I, Primrose B, Iturriza-Gomara M, Gallimore CI, Brown DW, M F, Moses PD, Gray JJ, Kang G. 2007. Human caliciviruses in symptomatic and asymptomatic infections in children in Vellore, South India. J Med Virol 79:544-551.

Murata T, Katsushima N, Mizuta K, Muraki Y, Hongo S, Matsuzaki Y. 2007. Prolonged norovirus shedding in infants $<$ or $=6$ months of age with gastroenteritis. Pediatr Infect Dis J 26:46-49.

Murray TY, Mans J, Taylor MB. 2013a. Human calicivirus diversity in wastewater in South Africa. J Appl Microbiol 114:1843-1853.

Murray TY, Mans J, Taylor MB. 2013b. First detection of human sapoviruses in river water in South Africa. Water Sci Technol 67:2776-2783.

Nakata S, Honma S, Numata K, Kogawa K, Ukae S, Adachi N, Jiang X, Estes MK, Gatheru Z, Tukei PM, Chiba S. 1998. Prevalence of human calicivirus infections in Kenya as determined by enzyme immunoassays for three genogroups of the virus. J Clin Microbiol 36:3160-3163.

Okada M, Ogawa T, Yoshizumi H, Kubonoya H, Shinozaki K. 2007. Genetic variation of the norovirus GII-4 genotype associated with a large number of outbreaks in Chiba prefecture, Japan. Arch Virol 152:2249-2252.

Oldak E, Sulik A, Rozkiewicz D, Liwoch-Nienartowicz N. 2012. Norovirus infections in children under 5 years of age hospitalized due to the acute viral 
gastroenteritis in northeastern Poland. Eur J Clin Microbiol Infect Dis 31:417422.

Phan TG, Trinh QD, Yagyu F, Okitsu S, Ushijima H. 2007. Emergence of rare sapovirus genotype among infants and children with acute gastroenteritis in Japan. Eur J Clin Microbiol Infect Dis 26:21-27.

Puustinen L, Blazevic V, Huhti L, Szakal ED, Halkosalo A, Salminen M, Vesikari T. 2012. Norovirus genotypes in endemic acute gastroenteritis of infants and children in Finland between 1994 and 2007. Epidemiol Infect 140:268-275.

Rockx B, De Wit M, Vennema H, Vinje J, De Bruin E, Van Duynhoven Y, Koopmans M. 2002. Natural history of human calicivirus infection: a prospective cohort study. Clin Infect Dis 35:246-253.

Rodriguez-Guillen L, Vizzi E, Alcala AC, Pujol FH, Liprandi F, Ludert JE. 2005. Calicivirus infection in human immunodeficiency virus seropositive children and adults. J Clin Virol 33:104-109.

Sano D, Pérez-Sautu U, Guix S, Pintó RM, Miura T, Okabe S, Bosch A. 2011. Quantification and genotyping of human sapoviruses in the Llobregat river catchment, Spain. Appl Environ Microbiol 77:1111-1114.

Schorn R, Hohne M, Meerbach A, Bossart W, Wuthrich RP, Schreier E, Muller NJ, Fehr T. 2010. Chronic norovirus infection after kidney transplantation: molecular evidence for immune-driven viral evolution. Clin Infect Dis 51:307314.

Sdiri-Loulizi K, Ambert-Balay K, Gharbi-Khelifi H, Sakly N, Hassine M, Chouchane S, Guediche MN, Pothier P, Aouni M. 2009. Molecular epidemiology of norovirus gastroenteritis investigated using samples collected from children in Tunisia during a four-year period: detection of the norovirus variant GGII.4 Hunter as early as January 2003. J Clin Microbiol 47:421-429.

Siebenga JJ, Vennema H, Renckens B, de Bruin E, van der Veer B, Siezen RJ, Koopmans M. 2007. Epochal evolution of GGII.4 norovirus capsid proteins from 1995 to 2006. J Virol 81:9932-9941.

Svraka S, Vennema H, van der Veer B, Hedlund KO, Thorhagen M, Siebenga J, Duizer E, Koopmans M. 2010. Epidemiology and genotype analysis of emerging sapovirus-associated infections across Europe. J Clin Microbiol 48:2191-2198.

Teunis PF, Moe CL, Liu P, Miller SE, Lindesmith L, Baric RS, Le Pendu J, Calderon RL. 2008. Norwalk virus: how infectious is it? J Med Virol 80:1468-1476.

Trang NV, Luan le T, Kim-Anh le T, Hau VT, Nhung le TH, Phasuk P, Setrabutr O, Shirley H, Vinje J, Anh DD, Mason CJ. 2012. Detection and molecular characterization of noroviruses and sapoviruses in children admitted to hospital with acute gastroenteritis in Vietnam. J Med Virol 84:290-297.

Trujillo AA, McCaustland KA, Zheng DP, Hadley LA, Vaughn G, Adams SM, Ando T, Glass RI, Monroe SS. 2006. Use of TaqMan real-time reverse transcriptionPCR for rapid detection, quantification, and typing of norovirus. J Clin Microbiol 44:1405-1412.

Wingfield T, Gallimore CI, Xerry J, Gray JJ, Klapper P, Guiver M, Blanchard TJ. 2010. Chronic norovirus infection in an HIV-positive patient with persistent diarrhoea: a novel cause. J Clin Virol 49:219-222.

Zheng DP, Ando T, Fankhauser RL, Beard RS, Glass RI, Monroe SS. 2006. Norovirus classification and proposed strain nomenclature. Virology 346:312323. 